Available online on 15.11.2019 at http://ujpr.org
Universal Journal of Pharmaceutical Research
Th International Peer Reviewed Journal
Open access to Pharmaceutical research

\title{
IN VITRO DISSOLUTION STUDY OF GLIMEPIRIDE FROM BINARY AND TERNARY SOLID DISPERSION FORMULATION Sharmin Akhter $\left.{ }^{1}{ }^{(}\right)$, Md. Sajjad Hossen ${ }^{1}{ }^{(D}$, Md. Salahuddin ${ }^{2}{ }^{(}$, Muazzem Ahmed Sunny ${ }^{1}$, Farzana Akther Sathi ${ }^{3}$ (D) Md. Shahidul Islam ${ }^{* 4}$ (D) \\ ${ }^{I}$ Department of Pharmacy, BGC Trust University, Bangladesh. \\ ${ }^{2}$ Bimco Animal Health Ltd. Bangladesh. \\ ${ }^{3}$ The Acme Laboratories Ltd. Bangladesh. \\ ${ }^{4 *}$ Department of Pharmacy, University of Science and Technology Chittagong (USTC), Bangladesh.
}

\section{ABSTRACT}

Objective: Glimepiride (GMP) is poorly water soluble drug, so solubility is the main constraint for its oral bioavailability. Because, poor aqueous solubility and slow dissolution rate of the glimepiride lead to irreproducible clinical response or therapeutic failure in some cases due to sub therapeutic plasma drug levels.

Methods: In this study, binary and ternary solid dispersion of glimepiride were prepared with polyethylene glycol 6000 (PEG 6000) and polyethylene glycol 4000 (PEG 4000) at different weight ratios using the solvent evaporation and melting method.

Results: It was found the drug was released $0.46 \%$ after 5 minutes and only $15.83 \%$ within 60 minutes from active glimepiride on the other hand the release pattern of glimepiride from the binary formulation containing PEG 4000 in 1:5 (Formulation coding: G5) showed the best result.

Conclusion: It was found that the ternary different SD formulation containing (PEG4000: Glimepiride: Povidone) in ratio 1:1:0.25 (Formulation G13) showed the best result. The drug was changed to amorphous form after solid dispersion. It was also evident that solid dispersions improve solubility of drug particles thus enhancing dissolution characteristics of drugs they increase the oral bioavailability.

Keywords: Fusion method, glimepiride, poorly soluble drug.

Article Info: Received 2 September 2019; Revised 8 October; Accepted 1 November, Available online 15 November 2019

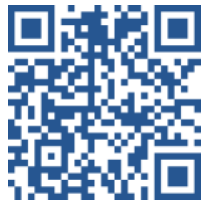
Cite this article-

Akhter S, Hossen MS, Salahuddin M, Sunny MA, Sathi FA, Islam MS.In vitro dissolution study of glimepiride from binary and ternary solid dispersion formulation. Universal Journal of Pharmaceutical Research 2019; 4(5):7-11

DOI: https://doi.org/10.22270/ujpr.v4i5.310

Address for Correspondence

Md. Shahidul Islam, Assistant Professor, Department of Pharmacy, University of Science and Technology Chittagong (USTC) Bangladesh. E-mail: s_i_liton@yahoo.com

\section{INTRODUCTION}

It has studied that, improving oral bioavailability of drugs those given as solid dosage forms remains a challenge for the formulation scientists due to solubility problems. Most of the newly invented chemical entities are poorly water soluble. As a result formulating them as oral solid dosage forms is a hurdle to the specialists. Many techniques have been exercised to improve oral bioavailability of drugs ${ }^{1}$. The rate of dissolution and solubility should not be confused as they are different concepts, kinetic and thermodynamic, respectively. The solubilization kinetics, as well as apparent solubility can be improved after complexation of an active ingredient with cyclodextrin. This can be used in the case of drug with poor solubility ${ }^{2}$. The oral route of administration is the most preferred and widely acceptable route of delivery due to ease of ingestion for many drugs. Drugs with slow dissolution rate show the incomplete absorption leading to low bioavailability when orally administered ${ }^{3}$. Many of the drugs belong to class II of the biopharmaceutical classification system showing poor solubility and high permeability Glimepiride shows low, $\mathrm{pH}$ dependent solubility. In acidic and neutral aqueous media, glimepiride exhibits very poor solubility at $37^{\circ} \mathrm{C}(<0.004 \mathrm{mg} / \mathrm{ml})$. In media $\mathrm{pH}>7$, solubility of drug is slightly increased to $0.02 \mathrm{mg} / \mathrm{ml}$. These poor water soluble drugs provide challenges to deliver them in an active and absorbable form to the desired absorption site using physiologically safe excipients Therefore; one of the most important steps in the development of dosage forms for these drugs is to improve their solubility and/or dissolution rate. Chiou and Rigelman and Serajuadin et al., have used 
the solid dispersion (SD) technique for dissolution enhancement of poorly water-soluble drugs ${ }^{4}$. Among the various approaches, the SD technique has often proved to be the most successful in improving the dissolution and bioavailability of poorly soluble active pharmaceutical ingredients because it is simple, economic, and advantageous. Sekiguchi and Obi were the first to propose the SD method using water-soluble carriers to improve the dissolution characteristics of poorly water-soluble drugs. Many water-soluble carriers have been employed for preparation of SD of poorly soluble drugs ${ }^{5}$. The most common are polyethylene glycols, polyvinyl pyrrolidone, mannitol and hydroxypropyl methylcellulose. Due to poor solubility in GI fluids, it results in low and erratic oral bioavailability ${ }^{6}$. Glimepiride was selected as a model drug for dissolution enhancement studies in the present investigation. Attempts were made to enhance the dissolution of GMP using a SD technique. SDs of GMP with PVP K 30 was prepared in different ratios using solvent evaporation method and then tablets of best formulation of SD were formulated by using direct compression $\operatorname{method}^{7}$. Tablet formulations were prepared by direct compression technique using super disintegrates povidone in different concentrations ${ }^{8}$. Glimepiride is a poorly water-soluble oral hypoglycemic drug exhibiting poor dissolution pattern'. The purpose of this work was to increase the dissolution rate of glimepiride by formation of solid dispersion with different water soluble carriers. Solid dispersion of glimepiride were prepared with polyvinyl pyrrolidone K-30, poloxamer 407, polyethylene glycol 6000 (PEG 6000), polyethylene glycol 4000 (PEG 4000), sodium starch glycolate, ludiflash and lactose at different weight ratios using the solvent evaporation and melting method ${ }^{10}$. Physical mixtures of the poloxamer 407 and povidone K-30 with glimepiride at different ratios were also used. In compare to physical mixtures with povidone K-30 and poloxamer 407, drug release from physical mixture PM (1/9) PVP K-30 was higher $(65.93 \%$ within $5 \mathrm{~min})$ than drug release from physical mixture with poloxamer 407 (56\% within 5 $\mathrm{min}$ ) the drug release from pure drug was $6.84 \%$ within 5 minError! Reference source not found.. With the recent development in the screening of potential therapeutic agents, the number of poorly water soluble drugs have risen sharply and gained large interest due to the challenges in the oral solubility of the drug which leads to the major cause for which the techniques are meant to be implemented. One amongst such techniques is the formulation of solid dispersion for the solubility enhancement ${ }^{12,16,18}$.

\section{MATERIALS AND METHODS}

Glimepiride was obtained from Eskayef Bangladesh ltd, Gazipur. PEG 4000, PEG 6000 were obtained from Albion laboratories ltd, Eudragit was obtained from The Acme laboratories 1td. Other reagents used were of analytical grade.

\section{Preparation of solid dispersion formulation}

Fusion method was used for the preparation of solid dispersion of glimepiride. Desired amount out of drug and polymers in different ratio were weighted out accurately and taken in a beaker and melted at $70^{\circ} \mathrm{C}$.

The mixture was stirred vigorously for uniform mixing and was kept in normal room temperature for 72 hour until a solid mass was formed. Solidified mixture was then grinded thoroughly with the help of mortar and pestle. Then the powdered particle passed through a sieve (mesh size 40).
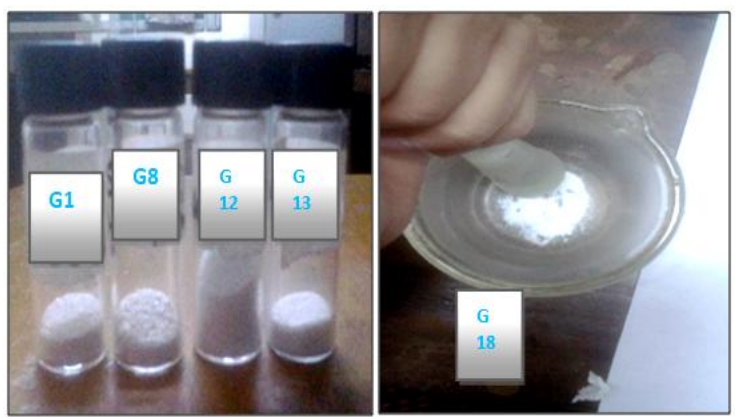

Figure 1: Solid dispersion formulations of different batches.

The resulted solid dispersion formulations were weighted and transferred in a fresh vial and kept in a dessicator until further investigation.

Table 1: Formulation of binary and ternary solid dispersion of glimepiride prepared by fusion method using different polymer at different ratio.

\begin{tabular}{|c|c|c|c|}
\hline Batch & Carriers & $\begin{array}{c}\text { Drug } \\
\text { polymer } \\
\text { ratio }\end{array}$ & $\begin{array}{c}\text { Dispensing } \\
\text { (mg) }\end{array}$ \\
\hline G1 & PEG4000 & $1: 1$ & $300: 300$ \\
\hline G2 & PEG4000 & $1: 2$ & $300: 600$ \\
\hline G3 & PEG4000 & $1: 3$ & $300: 900$ \\
\hline G4 & PEG4000 & 1:4 & $300: 1200$ \\
\hline G5 & PEG4000 & $1: 5$ & $300: 1500$ \\
\hline G6 & PEG6000 & $1: 1$ & $300: 300$ \\
\hline G7 & PEG6000 & $1: 2$ & $300: 600$ \\
\hline G8 & PEG6000 & $1: 3$ & $300: 900$ \\
\hline G9 & PEG600 & $1: 4$ & 300:1200 \\
\hline G10 & PEG6000 & $1: 5$ & $300: 1500$ \\
\hline G11 & $\begin{array}{l}\text { PEG4000:GLM: } \\
\text { POVIDONE }\end{array}$ & 1:1:0.75 & $200: 200: 150$ \\
\hline G12 & $\begin{array}{l}\text { PEG4000:GLM: } \\
\text { POVIDONE }\end{array}$ & 1:1:0.50 & 200:200:100 \\
\hline G13 & $\begin{array}{l}\text { PEG4000:GLM: } \\
\text { POVIDONE }\end{array}$ & $1: 1: 0.25$ & 200:200:50 \\
\hline G14 & $\begin{array}{l}\text { PEG4000:GLM: } \\
\text { POVIDONE }\end{array}$ & 1:1:00 & 200:200:00 \\
\hline G15 & $\begin{array}{l}\text { PEG6000:GLM: } \\
\text { POVIDONE }\end{array}$ & $1: 1: 0.75$ & $200: 200: 150$ \\
\hline G16 & $\begin{array}{l}\text { PEG60000:GLM: } \\
\text { POVIDONE }\end{array}$ & $1: 1: 0.50$ & 200:200:100 \\
\hline G17 & $\begin{array}{l}\text { PEG600:GLM: } \\
\text { POVIDONE }\end{array}$ & $1: 1: 0.25$ & 200:200:50 \\
\hline G18 & $\begin{array}{l}\text { PEG600:GLM: } \\
\text { POVIDONE }\end{array}$ & $1: 1: 00$ & 200:200:00 \\
\hline
\end{tabular}

In-vitro dissolution test for Glimepiride and solid dispersion formulation

The in vitro dissolution studies for Glimepiride drug and SD formulation were performed using USP 
dissolution test apparatus type II (paddle type) method using $900 \mathrm{ml}$ of phosphate buffer $(\mathrm{pH} 7.8)$ as dissolution medium. The temperature of the medium was maintained at $\left(37 \pm 0.5^{\circ} \mathrm{C}\right)$ throughout the experiment. The samples contained glimepiride or its equivalent solid dispersion were placed in the dissolution medium. Paddle was used at a stirring rate of $75 \mathrm{rpm}$. A $5 \mathrm{ml}$ aliquot was withdrawn at predetermined time intervals of $5,15,30,45$, and 60 min and then $5 \mathrm{ml}$ of fresh dissolution medium was replaced to maintain the constant volume of dissolution medium. The absorbance value of the collected samples was measured at $273 \mathrm{~nm}$ using UV-visible spectrophotometer against dissolution medium as blank. The percent release of drug was calculated using the equation obtained from the standard curve in the media $^{19}$.

\section{RESULTS AND DISCUSSION}

The aims of present investigation was to enhance the dissolution rate of poorly water soluble drugs glimepiride by preparing the solid dispersion using povidone, PEG 4000, PEG 6000. In current study18 SD dispersion formulations of glimepiride were prepared by Fusion method using different soluble polymers. When glimepiride were dispersed in polymer, its dissolution were enhanced significantly compared with active glimepiride.

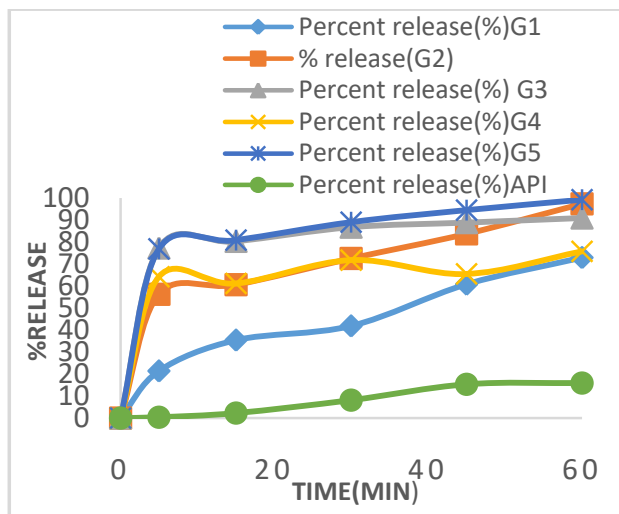

Figure 2: Average \% release of drug from binary SD formulation containing PEG 4000 with different ratio.

In this study fusion/melting method was used for the preparation of solid dispersion of glimepiride.

Dissolution profile of active Glimepiride

$10 \mathrm{mg}$ of pure Glimepiride was used for dissolution study.

It was found that only $0.46 \%$ drug was released after 5 minutes and $15.83 \%$ was released within 60 minutes time interval. This showed that dissolution profile of glimepiride was very poorly.

In vitro dissolution study of binary and ternary solid dispersion of glimepiride (fusion method)

Solid dispersion of glimepiride with PEG 4000 at different ratio G1 (1:1), G2 (1:2), G3 (1:3), G4 (1:4), G5 (1:5) and active glimepiride (API) were used for dissolution study. It was found that only $0.46 \%$ from active glimepiride, $21.46 \%$ from formulation G1, $56.30 \%$ from $\mathrm{G} 2, \mathbf{7 7 . 3 0 \%}$ from G3, $64.15 \%$ from $\mathrm{G} 4$ and $76.84 \%$ from G5, were released after $5 \mathrm{~min}$ and $60.77 \%$ from G1, $83.66 \%$ from $\mathrm{G} 2,88.83 \%$ from $\mathrm{G} 3$, $65.47 \%$ from G4, $94.36 \%$ from G5, $15.29 \%$ from active glimepiride were released after $45 \mathrm{~min}$. Finally $72.88 \%$ from $\mathrm{G} 1,97.27 \%$ from $\mathrm{G} 2,90.91 \%$ from $\mathrm{G} 3$, $75.75 \%$ from G4, $99.76 \%$ from G5 were released within an hour time interval.

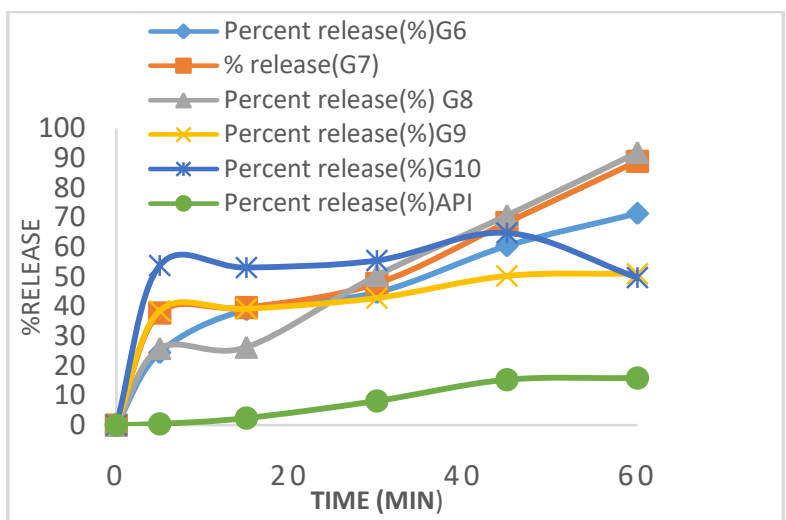

Figure 3: Average \% release of drug from SD formulation containing PEG 6000 with different ratio

Whereas only $15.83 \%$ was released from active glimepiride in 1 hour. From the obtained data (Figure 2) we can conclude that, the release pattern of drug from SD formulation containing PEG 4000 has increased gradually when the amount of PEG 4000 was increased. It was observed that solid dispersion formulation G5 showed substantially better result in $1: 5$ ratio in comparison to those of $\mathrm{G} 1, \mathrm{G} 2, \mathrm{G} 3$, and G4.

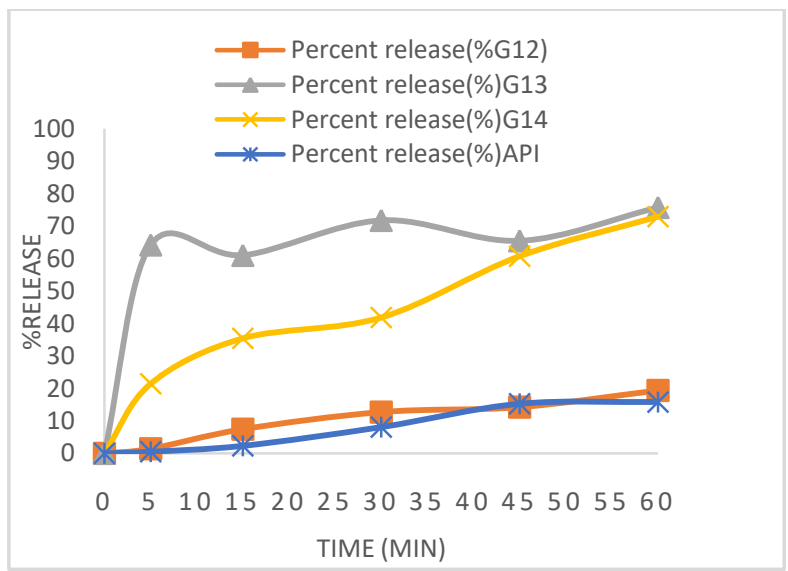

Figure 4: Average \% release of drug from ternary SD formulation containing PEG 4000 and Povidone.

Comparative dissolution profile of active glimepiride and solid dispersion formulation (Glimepiride+PEG 6000) for their different ratio.

Solid dispersion of glimepiride with PEG 6000 at different ratio G6 (1:1), G7 (1:2), G8 (1:3), G9 (1:4), and G10 (1:5) were used for dissolution study. It was found that $24.46 \%$ from G6, $37.86 \%$ from G7, $25.84 \%$ from G8, 38.53\% from G9, 53.76\% from G10 were released after $5 \mathrm{~min}$ and $60.36 \%$ from G6, $68.30 \%$ from $\mathrm{G} 7,70.72 \%$ from G8, $50.28 \%$ from G9, and $64.82 \%$ from G10 were released after $45 \mathrm{~min}$. Finally 
71.31\% from G6, 88.99\% from G7, 91.87\% from G8, $51.01 \%$ from G9 and $49.71 \%$ from G10 were released within an hour time interval. From the obtained data (Figure3) it was found that, the release pattern from SD formulation containing PEG 6000 has increased gradually when the amount of PEG 6000 was decreased. It was observed that solid dispersion formulation G8 showed their better result in 1:3 ratios in comparison to those of G6, G7, G9, and G10.

Comparative dissolution profile of active glimepiride and solid dispersion (Glimepiride+ PEG 4000+ Povidone) for their different ratio

Ternary SD formulation of Glimepiride containing PEG 4000 and Povidone at different ratios of G11 (1:1:0.75), G12 (1:1:0.50), G13 (1:1:0.25), G14 (1:1:0) and API were used for dissolution study. It was found that $6 \%$ from $\mathrm{G} 11,1.38 \%$ from $\mathrm{G} 12,64.15 \%$ from G13, $21.46 \%$ from G14 and $0.46 \%$ from API were released after $5 \mathrm{~min}$ and $11.48 \%$ from G11, $14.19 \%$ from G12, $65.47 \%$ from G13, $60.77 \%$ from G14, $15.29 \%$ from API were released after $45 \mathrm{~min}$. Finally $24.69 \%$ from $\mathrm{G} 11,19.35 \%$ from $\mathrm{G} 12,75.75 \%$ from G13, $72.88 \%$ from G14 and $15.83 \%$ from API were released in an hour time interval.

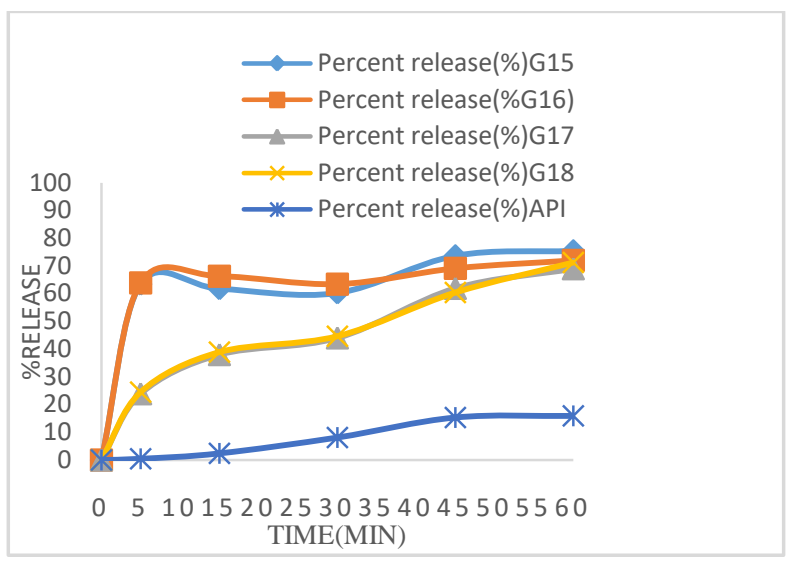

Figure 5: Percent release from ternary SD formulations of glimepiride containing PEG 6000 and Povidone.

From the obtained data (Figure4) we can conclude that the release pattern from the glimepiride containing two water soluble polymer PEG 4000 and Povidone have increased gradually when the amount of second polymer povidone were decreased in different ratio. It was observed SD formulation G13 (1:1:0.75) gave the best result in comparison to those of G11, G12, G14.

Comparative dissolution profile of pure glimepiride and solid dispersion formulation (Glimepiride+ PEG 6000+ Povidone) for their different ratio

Ternary SD formulation of Glimepiride containing PEG 6000 and Povidone at different ratio of G15 (1:1:0.75), G16 (1:1:0.50), G17 (1:1:0.25), G17 (1:1:0) and API were used in dissolution study. It was found that $63.46 \%$ from $\mathrm{G} 15,63.92 \%$ from G16, $23.90 \%$ from G17, $24.46 \%$ from G18 and $0.46 \%$ from API were released after $5 \mathrm{~min}$ and $73.71 \%$ from G15, $69.14 \%$ from $\mathrm{G} 16,61.84 \%$ from $\mathrm{G} 17,60.36 \%$ from G18, $15.29 \%$ from API were released after $45 \mathrm{~min}$.
Finally $75.50 \%$ from G15, 72.06\% from G16, 69.09\% from G17, $71.31 \%$ from G18 and $15.83 \%$ from API were released in an hour interval.

From the obtained data (Figure 5) we can conclude that the release pattern from the glimepiride containg two water soluble polymer PEG 6000 and Povidone has increased gradually when the amount of second polymer povidone were increased in different ratio. It was observed SD formulation G15 (1:1:0.75) gave the best result in comparison to those of G16, G17, G18.

Effect of the polymer on the improvement of solubility and dissolution rate of poorly water soluble glimepiride

From the above analysis of the result showed in figure number all of the formulation of soliddispersion of glimepiride successfully made their enhancement of release profile of active glimepiride. It was proved that the water soluble polymers were exclusively able to change the drug in the micro level and finally crystal glimepiride was formed to the amorphous state. There is lots of effect to increase the solubility of poorly water soluble drug. Such as polyethylene glycol (PEG) have the ability to solubilize the drug and improve wettability. The solid dispersion of glimepiride with PEG 6000 and PEG 4000 may be useful to increase the stability, solubility, dissolution and bioavailability of poorly water soluble drug. Another povidone is suitable for the manufacturing of solid dispersion as it possesses forms water soluble complexes with many active drugs. It also act as binder, bioavailability enhancer and taste master ${ }^{13,14}$.

Eudragit has a lower content of quaternary ammonium group in the structure and is considered as more permeable to water.Poloxamer act as solubilizing agent and plasticizer for enhancing the solubility and bioavailability of poorly soluble drugs in solid dosage forms. These water soluble polymers may operate in the micro environment immediately surrounding the drug particles in the early stage of dissolution, since the carrier completely dissolves in short time thus enhancing the solubility and dissolution of drug. Finally it can be concluded that dissolution rate of glimepiride was increased by solid dispersion technique which is due to the wettability and spread ability of the precipitated drug by reducing aggregation in the readily soluble state ${ }^{17}$.

\section{CONCLUSION}

Solid dispersion has attracted considerable interest as an efficient means of improving the dissolution rate and bioavailability of hydrophobic drugs.Glimepiride is an oral blood sugar-lowering drug in a class of medicine for controlling diabetes called Sulfonylurea. In the present study, solid dispersions of Glimepiride with different hydrophilic carriers in different ratios were prepared by physical mixing and fusion method to improve water solubility and dissolution characteristics. The preparation of solid dispersion of Glimepiride by fusion method has been proven to be successful. This research showed that when Glimepiride was dispersed in suitable water-soluble carriers such as PEG 6000, PEG 4000 and Povidone. Its dissolution was enhanced as compared with pure 
drug. It was found the drug was released $0.46 \%$ after 5 minutes and only $15.83 \%$ within 60 minutes from active glimepiride on the other hand the release pattern of glimepiride from the binary formulation containing PEG 4000 in 1:5 (Formulation coding: G5) showed the best result. It was found that the ternary different SD formulation containing (PEG4000: Glimepiride: Povidone) in ratio 1:1:0.25 (Formulation coding were: G13) showed the best result. In-vitro dissolution data also proves that percent release of drug from binary SDs was not similar with ternary SDs. The water soluble carrier may operate in the micro environment (diffusion layer) immediately surrounding the drug particles in the early stage of dissolution, since the carrier completely dissolves in short time thus enhancing the solubility and dissolution of drug.

\section{AUTHOR'S CONTRIBUTION}

The manuscript was carried out, written, and approved in collaboration with all authors.

\section{ACKNOWLEDGEMENTS}

The authors extend their thanks and appreciation to the University of Science and Technology Chittagong (USTC) Bangladesh to provide necessary facilities for this work.

\section{CONFLICT OF INTEREST}

No conflict of interest associated with this work.

\section{REFERENCES}

1. Dahlberg C, Millqvist-Fureby A, Schuleit M. Surface comparison and contact angle relationship for differently prepared solid dispersion. Europ J Pharm Bio-pharm 2008; 70(2): 478-485.

https://doi.org/10.1016/j.ejpb.2008.05.026

2. Singh S, Baghel RS, Yadav L. A review on solid dispersion. Int J Pharm Life Sci 2011; 2(9): 1078-1095.

3. Costantino HR, Firouzabadian L, Wu C, Carrasquillo KG, Griebenow K, Zale SE, et al. Protein spray freeze drying. Effect of formulation variables on particle size and stability. J Pharm Sci 2002; 91(2): 388-395. https://doi.org/10.1002/jps.10059

4. Chiou WL, Riegelman S. Preparation and dissolution characteristics of several fast-release solid dispersions of griseofulvin. J Pharm Sci 1969; 58: 1505-1510. https://doi.org/10.1002/jps.2600581218

5. Deepti, Dureja H, Madan AK. Solid dispersion adsorbates for enhancement of dissolution rates of drugs. PDA J Pharm Sci Tech 2007; 61(2): 97-101.
6. Bandarkar FS, Khattab IS. Lyophilized Gliclazide poloxamer solid dispersions for enhancement of in vitro dissolution and in vivo bioavailability. Int $\mathrm{J}$ Pharmacy Pharm Sci 2011; 3: 122-127 https://doi.org/10.1016/j.jddst.2018.06.005

7. Chiou WL, Riegelman S. Pharmaceutical applications of solid dispersion systems. J Pharm Sci 1971; 60: 12811302.https://doi.org/10.1002/jps.2600600902

8. Nasir ASM, Aarti MJ, Manoj M, Bari, Randhir B, Chavhan, Barhate SD.New dimensions to Solid Dispersion. Indo Am J Pharm Res 2013; 3(4): 3247.https://doi.org/10.7324/JAPS.2012.21031

9. Arunachalam A, Karthikeyan M, Konam K, Prasad PH, Sethuraman S, Kumar AA. A review on solid dispersion. Curr Pharm Res 2010; 1(82): 82-90. https://doi.org/10.7324/JAPS.2012.21031

10. Sonpal RN, Lalwani AN, Darji VC, Patel KR. Solid dispersion; an efficient tool for increasing bioavailability of poorly soluble drugs. Int J Pharm Sci Rev Res 2011; 8(1): 44-45. https://doi.org/10.4103/2230-973X.96921

11. Agarwal P, Semimul A. A comprehensive review on sustained release matrix tablets: a promising dosage form. Universal J Pharm Res 2018; 3(6): 53-58. https://doi.org/10.22270/ujpr.v3i6.222

12. Dahlberg C, Millqvist-Fureby A, Schuleit M. Surface comparison and contact angle relationship for differently prepared solid dispersion. Europ J Pharm bio-pharm 2008; 70(2): 478-485.https://doi.org/10.1016/j.ejpb.2008.05.026

13. Kumar A, Kumar K. Solid dispersion-strategy to enhance solubility and dissolution of poorly water soluble drugs. Uni J Pharm Res 2017; 2(5): 54-59. https://doi.org/10.22270/jddt.v5i2.1060

14. Bhusnure OG, Kazi PA, Gholve SB, Ansari A, Kazi SN. Solid Dispersion: An evergreen method for solubility enhancement of poorly water soluble Drugs. Int J Res Pharm Chem 2014; 4(4):906-918.

15. Jajere UM, Achadu AE. Fabrication and characterization of ezetimibe solid dispersion for solubility enhancement. Universal J Pharm Res 2017; 2(1): 12-16. https://doi.org/10.22270/ujpr.v2i1.R3

16. Kim KT, Lee JY, Lee MY, Song CK, Choi J, Kim DD. Solid dispersions as a drug delivery system. J Pharm Invest 2011;41(3):125-142 https://doi.org/10.13040/IJPSR.0975-8232.4(6).2094-05

17. Islam MS, Rasheda AL. Development and in vitro dissolution study of binary and ternary solid dispersions of aceclofenac. Universal J Pharml Res 2019; 4(1): 2936.https://doi.org/10.22270/ujpr.v4i5.310

18. Mooter G: Evaluation of Inutec SP1 as a new carrier in the formulation of solid dispersions for poorly soluble drugs. Int J Pharm 2006; 316: 1-6. https://doi.org/10.1016/j.ijpharm.2006.02.025

19. Younis MA. Solid dispersion technology, a contemporary overview on a well established technique. Universal $\mathrm{J}$ Pharm Res 2017; 2(3): 15-19.

https://doi.org/10.22270/ujpr.v2i3.RW1 